\title{
INDIVIDUAL VARIATION IN THE VIGOR OF SELF POLLEN AND SELFED PROGENY IN HIBISCUS MOSCHEUTOS (MALVACEAE) ${ }^{1}$
}

\author{
Allison A. Snow ${ }^{2,3,6}$ And Timothy P. Spira ${ }^{4,5}$ \\ ${ }^{2}$ Department of Plant Biology, Ohio State University, Columbus, Ohio 43210; \\ ${ }^{3}$ University of Michigan Biological Station, Pellston, Michigan 49769; \\ ${ }^{4}$ Department of Biology, Georgia Southern University, Statesboro, Georgia 30460; and \\ ${ }^{5}$ Smithsonian Environmental Research Center, Edgewater, Maryland 21037
}

\begin{abstract}
In some self-compatible species, self pollen tubes grow more slowly than outcross pollen, presumably leading to low selfing rates when mixtures of self and outcross pollen reach the stigma simultaneously. Here we show that the competitive ability of self pollen differed among individuals of Hibiscus moscheutos. Self pollen tubes grew slower than outcross pollen in three plants, faster than outcross pollen in four plants, and showed no difference in five other plants (based on rates of callose plug formation). Levels of inbreeding depression were examined by comparing progeny from self and outcross pollinations in seven maternal families. Self pollination led to reduced seed number in only one maternal family, and a slight decrease in seed size was seen in two maternal families. Considerable inbreeding depression occurred later in the life cycle, and the degree of inbreeding depression varied among maternal families of 6-week-old plants. Our results demonstrate the potential for unpredictable effects of pollen competition on individual selfing rates, which in turn may affect progeny vigor. This complex situation contrasts with previous reports of species in which outcross pollen consistently outcompetes self pollen (cryptic self-incompatibility).
\end{abstract}

Cryptic self-incompatibility occurs when self pollination is capable of yielding seeds, yet mixtures of self and outcross pollen typically result in outcrossed progeny (Bateman, 1956; Levin, 1975; Weller and Ornduff, 1977; Bowman, 1987; Casper, Sayigh, and Lee, 1988; Cruzan and Barrett, in press). The mechanisms by which self genotypes are precluded have rarely been identified, but some combination of slower pollen tube growth and/or increased rates of embryo abortion in selfed seeds is probably responsible (Levin, 1975; Weller and Ornduff, 1991; Montalvo, 1992; Cruzan and Barrett, in press). Knowing whether self and outcross pollen differ in their pollen tube growth rates can help determine whether the potential for cryptic self-incompatibility occurs in a given species.

Slower growth of self pollen as compared to outcross has been shown in several self-compatible cultivated species (e.g., Sayers and Murphy, 1966; Levin, 1975; refs. in Marshall and Ellstrand, 1986). Aizen, Searcy, and Mulcahy (1990) demonstrated slower growth of self pollen in two clones of Dianthus chinensis; they also showed that differences in pollen tube growth rates may be difficult to detect unless self and outcross pollen are applied to the same flower. Surprisingly little is known about the competitive ability of self pollen in self-compatible wild species. Slower growth of self pollen tubes relative to outcross was found in Geranium caespitosum (Hessing, 1989) and Eichornia paniculata (Cruzan and Barrett, in press). In Chamaecrista fasciculata no differences were seen in the growth rates of self and outcross pollen when these pollen types were applied to separate flowers (Fenster and Sork, 1988); mixed pollinations led to nonrandom fertilization

\footnotetext{
' Received for publication 15 May 1992; revision accepted 22 October 1992.

The authors thank Dennis Whigham, Jay O'Neill, Denny Rice, Elizabeth Turner, and Jennifer Tressler for logistical assistance; and Brenda Casper, Mitch Cruzan, Michelle Dudash, Robert Klips, and Victoria Sork for comments on the manuscript.

' Author for correspondence (Ohio State address).
}

favoring outcross pollen in one of three individuals (Sork and Schemske, 1992).

Because little is known about the performance of compatible self pollen in competition with outcross pollen, we tested for such differences in rose mallow, Hibiscus moscheutos. Self-compatibility was demonstrated in two previous experiments, which showed no differences in the number of seeds per fruit from self vs. outcross pollen (Spira, 1989; Snow and Spira, 1991a). Earlier work alerted us to the possibility that pollen tube growth rates vary considerably among individuals (Snow and Spira, 1991a, b). If this is the case, examining average differences between self and outcross pollen from many plants might obscure variation that occurs among individuals. Therefore, the purpose of this study was to examine variation among individual plants in the vigor of self pollen relative to outcross. A secondary goal was to determine whether selfing led to inbreeding depression in a subset of these experimental plants.

\section{MATERIALS AND METHODS}

Biology of Hibiscus moscheutos - Rose mallow is a herbaceous perennial native to fresh and brackish marshes of the eastern United States. The plant produces many shoots from a large, woody rootstock, and does not spread vegetatively. Its buoyant, thick-coated seeds are probably dispersed by water (Blanchard, 1976), so it is unlikely that neighboring plants are closely related to one another.

Details of the reproductive ecology of $H$. moscheutos are given in Spira (1989), Snow and Spira (1991a, b), and Spira et al. (1992). Briefly, the large, one-day flowers are pollinated by solitary anthophorid bees (Ptilothrix bombiformis) and by bumblebees (Bombus spp.). At our study populations near Edgewater, Maryland, bees often delivered surplus pollen to the stigmas by midmorning, leading to competition among pollen tubes for available ovules. Average pollen tube growth rate was positively correlated 
with the number of seeds a plant sired when mixtures of pollen were applied to stigmas (Snow and Spira, 1991a).

Within-flower selfing is unlikely in $H$. moscheutos due to spatial separation of anthers and stigmas, but betweenflower selfing (geitonogamy) can occur. Large plants bear up to 20-30 flowers daily at the peak of the midsummer blooming season. Compared with many other species, however, the potential for geitonogamy is limited because only one or two flowers open on each shoot or branch tip on a given day. Outcrossing rates are probably high, but we have not measured them due to a lack of sufficient allozyme polymorphism (A. Snow and R. Klips, unpublished data).

Pollen tube growth rates - Pollen tube "races" were conducted by applying self and outcross pollen to separate stigmas on separate, labeled stylar branches of the same flower (details in Snow and Spira, 1991a, b). The plants in this study were part of a collection of over 60 haphazardly chosen genotypes that were taken from a natural population and grown outdoors in Edgewater, Maryland (Snow and Spira, 1991a).

In 1989 we hand-pollinated six to 19 flowers from each of 12 pot-grown plants. Flowers were bagged the day before anthesis to exclude pollinators. On the following morning, newly opened flowers were cut off at the base of the pedicel, placed in water, and maintained at $25 \mathrm{C}$ in the laboratory, where pollinations were performed. We alternated the order of the two pollination treatments, with no more than a 2 -min delay between pollinations on the same flower. Each flower on a given plant received outcross pollen from a different donor, and, for the most part, the same group of donors was used with all recipients.

Three hours after pollination, the styles were severed at the base. This incubation period was appropriate for determining the number of callose plugs per tube in a standardized midstylar region, providing a good estimate of relative pollen tube growth rates (faster tubes produce callose plugs sooner than slower tubes; Snow and Spira, 1991a). Stigmas were excised in order to count the number of pollen grains applied (about 50-75 per treatment), and styles were stored in cold $70 \% \mathrm{EtOH}$ to halt further pollen tube growth. Percent pollen germination was calculated by counting the number of pollen tubes in each stylar branch and dividing by the number of grains per stigma (Snow and Spira, 1991a, in press). To quantify relative pollen tube growth rates, we counted the number of callose plugs per tube in standardized cross-sectional areas, using the portion of the style near the convergence of pollen tubes from the two treatments (Snow and Spira, 1991a). Proportions were arcsine-transformed for statistical analysis; treatment effects were analyzed using paired $t$-tests. All statistical tests were conducted using SAS (SAS, 1985).

Seed production-In 1990 we obtained fruits from self or outcross pollen on seven of the 12 maternal plants described above. Pollen from one donor was applied to all stigmas of a previously bagged flower, and the flower was rebagged to prevent insect visits. Four hours after pollination, we removed the bags to prevent overheating; the stigmas were also removed at this time to preclude pollen contamination (pollen germinates within $1 \mathrm{hr}$, and tubes reach the base of the style by $3 \mathrm{hr}$; Snow and Spira,
TABLE 1. Relative growth rates of self and outcross pollen. Number of callose plugs per tube after $3 \mathrm{hr}$ is a measure of relative pollen tube growth rate (see text)

\begin{tabular}{ccccc}
\hline \hline \multirow{2}{*}{$\begin{array}{c}\text { Plant ID } \\
\text { number }\end{array}$} & $N$ & \multicolumn{2}{c}{ Number of callose plugs per tube } & \\
\cline { 2 - 4 } & $N$ & Self & Outcross & Significance \\
\hline 8 & 14 & 0.42 & 0.50 & ns \\
18 & 10 & $\underline{0.68}$ & 0.42 & $*$ \\
19 & 16 & $\underline{0.44}$ & 0.35 & $*$ \\
47 & 14 & $\underline{0.60}$ & 0.50 & $*$ \\
48 & 19 & $\underline{0.51}$ & 0.38 & $*$ \\
52 & 14 & 0.45 & 0.49 & ns \\
55 & 9 & 0.33 & 0.35 & ns \\
57 & 9 & 0.54 & 0.51 & ns \\
58 & 10 & 0.38 & $\underline{0.54}$ & $*$ \\
61 & 12 & 0.36 & $\underline{0.53}$ & $*$ \\
62 & 15 & 0.52 & 0.51 & ns \\
64 & 6 & 0.38 & $\underline{0.54}$ & $*$ \\
\hline
\end{tabular}

${ }^{a}$ Faster pollen type is underlined when difference is significant (paired $t$-tests; ${ }^{*} P<0.05$, ns if not significant); $N$ is number of flowers.

1991a). As before, a different outcross donor was used on each flower of a given plant. Fruits that were damaged by seed predators were discarded, resulting in sample sizes of six to 12 fruits per treatment from each plant.

We counted the number of normally developed seeds as well as the number of shriveled, aborted seeds per capsule. Normal seeds from each fruit were weighed to calculate the average mass of individual seeds.

Seed germination and seedling growth-Seeds from these fruits were tested for germinability by nicking the seed coat with a razor and planting them in shallow trays filled with potting soil. For each maternal plant, we used 100110 seeds per treatment (self vs. outcross), representing equal numbers of seeds from the available fruits. Due to logistical problems, only four of the seven maternal families were used in this phase of the study.

Seedling emergence was relatively synchronous (4-6 d), perhaps because we nicked the seed coats to induce germination. Ten days after planting, when all but a few germinable seeds had sprouted, we randomly selected ten seedlings per treatment for transplanting, using roughly equal numbers of seedlings from each outcross donor. Pairs of seedlings, one from each treatment, were transplanted to 4-cm-diam pots and cultivated in the greenhouse. This provided the opportunity for competition between selfed and outcrossed progeny, perhaps exaggerating any differences in their growth rates (and allowing small differences to be detected). Six weeks later, the aboveground portion of each plant was harvested, dried for $48 \mathrm{hr}$ at $60 \mathrm{C}$, and weighed. Treatment effects within maternal families were analyzed using paired $t$-tests.

\section{RESULTS}

Pollen tube growth rates - The performance of self pollen relative to outcross varied among plants (Table 1). Self pollen was significantly slower than outcross pollen in three plants, faster than outcross in four plants, and not different in the remaining five plants. No differences were seen between treatments in the percent of grains that 
TABLE 2. Effects of self vs. outcross pollen on number of seeds per fruit and individual seed mass per fruit in seven individuals

\begin{tabular}{clrccl}
\hline \hline $\begin{array}{c}\text { Plant ID } \\
\text { number }\end{array}$ & $\begin{array}{c}\text { Type of } \\
\text { cross }\end{array}$ & $N$ & $\begin{array}{c}\text { Number } \\
\text { of normal } \\
\text { seeds }\end{array}$ & $\begin{array}{c}\text { Number } \\
\text { of aborted } \\
\text { seeds }\end{array}$ & $\begin{array}{c}\text { Individual } \\
\text { seed mass } \\
\text { (mg) }\end{array}$ \\
\hline \multirow{2}{*}{8} & Self & 9 & $89(9)$ & $16(5)$ & $6.5(0.01)$ \\
& Outcross & 6 & $112(13)$ & $13(4)$ & $7.2(0.04)$ \\
18 & Self & 11 & $95(10)$ & $17(8)$ & $7.9(0.03)$ \\
& Outcross & 7 & $108(6)$ & $7(2)$ & $8.7(0.04)$ \\
47 & Self & 10 & $102(9)$ & $16(4)$ & $8.2(0.02)$ \\
& Outcross & 11 & $120(2)$ & $8(2)$ & $8.9(0.01)^{* *}$ \\
52 & Self & 8 & $110(4)$ & $10(3)$ & $8.6(0.01)$ \\
& Outcross & 11 & $83(12)$ & $25(11)$ & $8.3(0.07)$ \\
55 & Self & 8 & $94(6)$ & $4(2)$ & $8.0(0.02)$ \\
& Outcross & 12 & $115(3)^{* *}$ & $2(1)$ & $9.3(0.03)^{* *}$ \\
62 & Self & 11 & $93(5)$ & $12(4)$ & $8.3(0.02)$ \\
& Outcross & 6 & $95(8)$ & $13(5)$ & $7.9(0.01)$ \\
64 & Self & 7 & $86(7)$ & $6(1)$ & $8.1(0.04)$ \\
& Outcross & 6 & $90(11)$ & $14(7)$ & $8.3(0.02)$ \\
Total & belf & 7 & $96(3)$ & $12(2)$ & $8.0(0.3)$ \\
& Outcross & 7 & $103(5)$ & $12(3)$ & $8.3(0.7)$ \\
\hline
\end{tabular}

${ }^{a}$ Means (1 SE) are shown; $N$ is number of fruits. Significance levels are ${ }^{*} P<0.05$ and ${ }^{* *} P<0.01$ based on $t$-tests for differences between pollination treatments.

${ }^{b}$ Average of seven individuals; see ANOVA in Table 3 for significance levels of main effects and interactions.

germinated (data not shown), which averaged 60\%-70\% as in previous studies (Snow and Spira 1991a, in press).

Seed production - Pollination treatment did not have a significant effect on the number of aborted seeds per fruit, and in general there was no effect on seed number or seed size (Tables 2,3 ). A notable exception was plant 55 , in which seeds from self pollen were fewer and smaller than those from outcross pollen. Selfed seeds were also significantly smaller in plant 47 . Lack of treatment effect could be due to small sample sizes $(N=6-12$ fruits per plant), although previous studies also showed no effect of self pollen on seed set (Spira, 1989; Snow and Spira, 1991a). Across maternal families, a mixed model ANOVA showed that pollen source was not significant as a main effect on seed size or on the number of normal or aborted seeds (Table 3). However, the interaction between pollen type and recipient was significant for seed number.

Seed germination and seedling growth - Selfing led to a significant decrease in seed germination in one of the four maternal families, whereas seedling biomass was reduced in three maternal families (Table 4; Fig. 1). Inbreeding depression was particularly strong at the germination stage for plant 55, and during seedling growth for plants 8 and 55. For example, selfed progeny from plant 8 attained only $36 \%$ of the mass of outcrossed progeny (Fig. 1).

\section{DISCUSSION}

We found no evidence for consistent differences between the growth rates of self and outcross pollen in this study of 12 individuals pollinated with an array of outcross genotypes. These results are similar to several previous comparisons involving only one or two outcross
TABLE 3. Mixed model ANOVA for effects of pollination treatment (self vs. outcross) and pollen recipient on seed production, with pollination treatment as a fixed effect and recipient as a random effect (means in Table 2)

\begin{tabular}{lrrrr}
\hline \hline$\quad$ Source of variation & df & $\begin{array}{c}\text { Type } \\
\text { III SS }\end{array}$ & $F$ & $P$ \\
\hline A. Number of normal seeds & & & & \\
$\quad$ Pollination treatment & 1 & 1,866 & 1.39 & 0.28 \\
Recipient & 6 & 5,885 & 1.74 & 0.12 \\
Cross $\times$ recipient & 6 & 8,084 & 2.39 & 0.03 \\
$\quad$ Error & 109 & 61,338 & & \\
B. Number of aborted seeds & & & & \\
Pollination treatment & 1 & 4 & 0.02 & 0.90 \\
Recipient & 6 & 2,344 & 1.48 & 0.19 \\
Cross $\times$ recipient & 6 & 2,297 & 1.45 & 0.20 \\
Error & 109 & 28,820 & & \\
C. Mean individual seed mass & & & \\
Pollination treatment & 1 & 0.0518 & 3.03 & 1.13 \\
Recipient & 6 & 0.3531 & 5.60 & 0.001 \\
Cross $\times$ recipient & 6 & 0.1025 & 1.63 & 0.15 \\
Error & 109 & 1.1449 & & \\
\hline
\end{tabular}

donors per recipient (Snow and Spira, 1991a). Therefore, we conclude that population-wide cryptic self-incompatibility due to pollen tube competition is unlikely.

Our results bear on other studies of relative pollen tube growth rates. In particular, the variation seen among individuals indicates that many genotypes should be included to test for consistent differences between self and outcross pollen tube growth rates. It is difficult to generalize from studies such as Aizen, Searcy, and Mulcahy (1990), which involved only two genetic clones of $\mathrm{Di}$ anthus chinensis. Experiments with $>10$ individuals of Chamaecrista fasciculata obtained results that are similar to ours (Fenster and Sork, 1988; Fenster, 1991; Sork and Schemske, 1992). Pollen tube growth rates of self and outcross pollen did not differ in C. fasciculata, and selfing resulted in inbreeding depression.

The differences we found among individuals in the vigor of self pollen suggest that some plants may be more prone

TABLE 4. Effects of self vs. outcross pollen on seed germination and mean seedling dry mass after 6 wk. Sample sizes for each maternal family were 100-110 seeds for germination and ten to 12 seedlings per cross type (number of paternal plants represented $=$ number of fruits listed in Table 2)

\begin{tabular}{clcc}
\hline $\begin{array}{c}\text { Maternal } \\
\text { family }\end{array}$ & \multicolumn{1}{c}{ Cross } & $\begin{array}{c}\text { Percent seed } \\
\text { germination }^{\mathbf{a}}\end{array}$ & $\begin{array}{c}\text { Seedling dry mass } \\
(\mathbf{m g})^{\mathbf{b}}\end{array}$ \\
\hline Plant 8 & Self & 86 & $288(38)$ \\
& Outcross & 86 & $801(66)^{* * *}$ \\
Plant 18 & Self & 66 & $493(47)$ \\
& Outcross & 76 & $618(60)^{*}$ \\
Plant 47 & Self & 79 & $344(84)$ \\
& Outcross & 84 & $361(46)$ \\
Plant 55 & Self & 65 & $207(27)$ \\
& Outcross & $87 * * *$ & $293(22)^{* * *}$ \\
\hline
\end{tabular}

a Cross effect tested using $G$-tests. Significance levels for differences between selfed and outcrossed progeny are ${ }^{*} P<0.05,{ }^{* *} P<0.01$, *** $P<0.001$.

${ }^{b}$ Cross effect tested using paired $t$-tests. Significance levels as above; $S E$ in parentheses. 


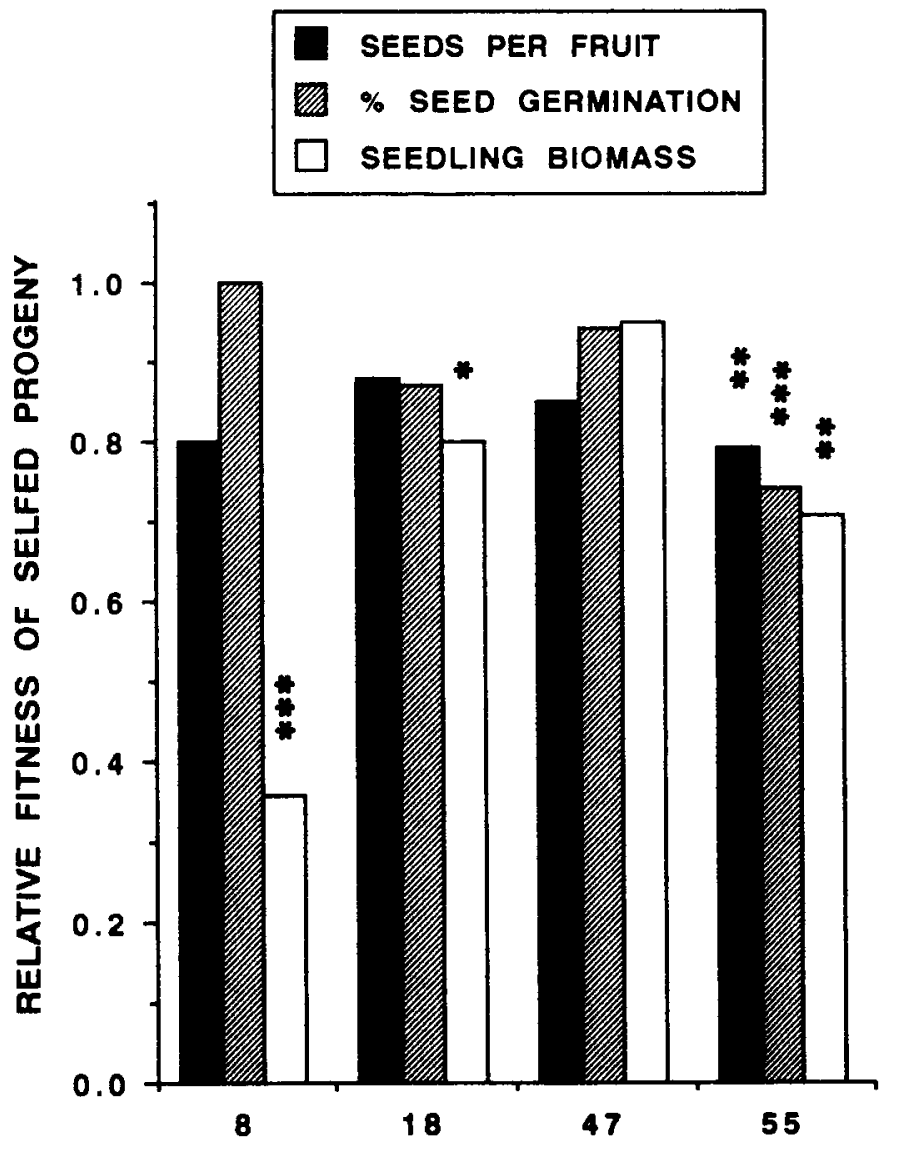

MATERNAL PLANT FAMILY

Fig. 1. Relative fitness of selfed progeny in four maternal families, calculated as the value for selfed progeny divided by the value for outcrossed (data from Tables 2, 4). Significant differences between self and outcross progeny indicated by ${ }^{*} P<0.05,{ }^{* *} P<0.01,{ }^{* * *} P<$ 0.001 .

to selfing than others when self and outcross pollen are deposited simultaneously. Genetic and/or environmental factors may be responsible for differences in pollen competitive ability, perhaps including the individual's history of selfing. In maize, for example, repeated generations of selfing led to slight but significant increases in the competitive ability of self pollen relative to outcross (Johnson and Mulcahy, 1978).

An alternative explanation for differences among individuals is that some plants simply have more vigorous pollen than others, regardless of whether their pollen is involved in selfing or outcrossing. For example, in plant 18 self pollen tubes grew faster than did outcross pollen tubes (Table 1), and subsequent studies showed that pollen tubes from this plant also grew significantly faster than those from a random sample of outcross donors when tested on unrelated recipients (Spira and Snow, unpublished data). Likewise, pollen from plants 58 and 64 produced slower tubes than pollen from other donors when used in both self and outcross pollinations (Table 1 and unpublished data). This may indicate that the interaction between self pollen and a plant's own pistil does not have an overriding effect on relative pollen performance. If so, the benefit of having pollen that can sire more seeds on other plants (cf. Snow and Spira, 1991b) could be offset by greater selfing rates and subsequent inbreeding depression in these plants.

We investigated levels of inbreeding depression in several maternal families. Our estimates of inbreeding depression were based on few individuals grown for a relatively short time period (6 wk past seed germination), and we did not compare self and outcross progeny under field conditions (cf. Dudash, 1990). Nonetheless, we documented reduced vigor in selfed progeny and found that the extent of inbreeding depression varied dramatically among maternal families. Dudash (1990) obtained similar results in an elegant study of Sabatia angularis. Variation among individuals in the extent of inbreeding depression is expected on the basis of presumed variation in genetic load (Charlesworth and Charlesworth, 1987).

In summary, our data on relative pollen tube growth rates suggest that the outcome of competition between self and outcross pollen tubes varies among individuals. Thus, pollen tube competition does not appear to be a general mechanism for enhancing the proportion of progeny that results from outcrossing in $H$. moscheutos.

\section{LITERATURE CITED}

Aizen, M. A., K. B. Searcy, AND D. L. Mulcahy. 1990. Among- and within-flower comparisons of pollen-tube growth following self- and cross-pollinations in Dianthus chinensis (Caryophyllaceae). American Journal of Botany 77: 671-676.

Bateman, A. J. 1956. Cryptic self-incompatibility in the wallflower: Cheiranthus cheiri L. Heredity 10: 257-261.

BLANChARD, O. J., JR. 1976. A revision of species segregated from Hibiscus sect. Trionium (Medicus) de Candolle sensu lato (Malvaceae). Ph.D. dissertation, Cornell University. Ithaca, NY.

Bowman, R. N. 1987. Cryptic self-incompatibility and the breeding system of Clarkia unguiculata (Onagraceae). American Journal of Botany 74: $471-476$.

CAsper, B. B., L. S. SAYIGH, AND S. S. Lee. 1988. Demonstration of cryptic incompatibility in distylous Amsinckia douglasiana. Evolution 42: 248-253.

Charlesworth, D., and B. Charlesworth. 1987. Inbreeding depression and its evolutionary consequences. Annual Review of Ecology and Systematics 18: 237-268.

Cruzan, M. B., and S. C. H. Barretr. In press. Contribution of cryptic incompatibility to the mating system of Eichornia paniculata (Pontederiaceae). Evolution.

DUDASH, M. R. 1990. Relative fitness of self and outcrossed progeny in a self-compatible, protandrous species, Sabatia angularis L. (Gentianaceae): a comparison in three environments. Evolution 44: 1129-1139.

Fenster, C. B. 1991. Gene flow in Chamaecrista fasciculata (Leguminosae). II. Gene establishment. Evolution 45: 410-422.

- - AND V. L. SORK. 1988. Effect of crossing distance and male parent on in vivo pollen tube growth in Chamaecrista (=Cassia) fasciculata. American Journal of Botany 75: 1898-1903.

Hessing, M. B. 1989. Differential pollen tube success in Geranium caespitosum. Botanical Gazette 150: 404-410.

Johnson, C. M., AND D. L. MulCaHY. 1978. Male gametophyte in maize. II. Pollen vigor in inbred plants. Theoretical and Applied Genetics 51: 211-215.

Levin, D. A. 1975. Gametophytic selection in Phlox. In D. L. Mulcahy [ed.], Gamete competition in plants and animals, 207-217. NorthHolland Publishers, Amsterdam.

Marshall, D. L., aNd N. C. Ellstrand. 1986. Sexual selection in Raphanus sativus: experimental data on nonrandom fertilization, maternal choice, and consequences of multiple paternity. American Naturalist 127: 446-461.

Montalvo, A. M. 1992. Relative success of self and outcross pollen 
comparing mixed- and single-donor pollinations in Aquilegia caerulea. Evolution 46: 1181-1198.

SAS INSTITUTE, INC. 1985. SAS user's guide: statistics. SAS Institute, Cary, NC.

SAYERS, E. R., AND R. P. MuRPHY. 1966. Seed set in alfalfa as related to pollen tube growth, fertilization frequency, and post-fertilization ovule abortion. Crop Science 6: 365-368.

Snow, A. A., AND T. P. SpIRA. 1991a. Differential pollen-tube growth rates and nonrandom fertilization in Hibiscus moscheutos (Malvaceae). American Journal of Botany 78: 1419-1426.

- AND —. 1991b. Pollen vigour and the potential for sexual selection in plants. Nature 352: 796-797.

, AND - In press. Germination as a component of pollen competitive ability in Hibiscus moscheutos. In E. Ottaviano, D. L. Mulcahy, M. Sari-Gorla, and G. Bergamini-Mulcahy [eds.], Angiosperm pollen and ovules. Springer-Verlag, New York, NY.
SORK, V. L., AND D. W. SCHEMSKE. 1992. Fitness consequences of mixed-donor pollen loads in the annual legume Chamaecrista fasciculata. American Journal of Botany 79: 508-515.

SPIRA, T. P. 1989. Reproductive biology of Hibiscus moscheutos (Malvaceae). In J. H. Bock and Y. B. Linhart [eds.], The evolutionary ecology of plants, 247-255. Westview Press, Boulder, CO.

- A. A. Snow, D. F. Whigham, and J. Leak. 1992. Flower visitation, pollen deposition, and pollen-tube competition in $\mathrm{Hi}$ biscus moscheutos (Malvaceae). American Journal of Botany 79: $428-433$.

Weller, S. G., AND R. ORNDUFF. 1977. Cryptic self-incompatibility in Amsinckia grandiflora. Evolution 31: 47-51.

, AND -. 1991. Pollen tube growth and inbreeding depression in Amsinckia grandiflora (Boraginaceae). American Journal of Botany 78: 801-804. 